Belmiro Valverde Jobim Castor, PhD

(University of Southern California) em

administração pública, professor na

Universidade Federal do

Paraná - U.F.P.R. e ex-secretário de

Planejamento do Estado do Paraná.

\title{
A Busca de uma tecnologia apropriada ao Brasil
}

Nota

O debate sobre tecnologia alternativa, apropriada ou intermediária, ocupa um sem número de estudiosos em todo o mundo. O presente trabalho, de autoria de Belmiro Valverde Jobin Castor é, porém, original, e constitui uma contribuição significativa para clarificar um ponto de vista brasileiro sobre o tema. Belmiro Castor destila a sua experiência como Secretário de Planejamento do Estado do Paraná de abril de 1974 a janeiro de 1979 e, com realismo crítico, aprecia a crônica inadequação ao contexto nacional de nossa política (ou falta de política) tecnológica. Outros estudiosos, antes dele, têm focalizado o assunto. Mas Belmiro Castor, neste trabalho, é o primeiro analista que examina a questão tecnológica do Brasil do ponto de vista da teoria da delimitação dos sistemas sociais. O presente estudo é desenvolvido em bases teóricas ainda pouco conhecidas no Brasil, e tem implicaç̃̃es pragmáticas, pertinentes ao domínio das políticas públicas. Sua relevância, por certo, será nota da pelos leitores interessados no debate tecnológico.

Florianópolis, 12 de junho 1980.

Alberto Guerreiro Ramos ${ }^{1}$

Sumário - Nota. Introdução. Modernidade, uniformidade e eficiência. Evolução e rumos da tecnologia. Características básicas da tecnologia apropriada. Tecnologia e teoria apropriadas. A $\mathrm{cool}$ no Brasil e tecnologia apropriada.

\section{Introdução}

A grande visibilidade nacional e internacional adquirida pelo projeto brasileiro de produção de álcool carburante trouxe à tona, mais uma vez, o problema das políticas tecnológicas vigentes em nosso país e seus reflexos sobre a sociedade.

Muito tem sido dito, em graus variados de substância e retórica, a respeito da necessidade de alterarmos, profundamente, os modelos pelos quais nos guiamos na escolha das tecnologia adotadas no Brasil. As críticas mais usuais referem-se à importação pelo país de processos desenvolvidos em e para países de maior adiantamento tecnológico, e que contribui para a nossa vulnerabilidade face ao exterior. Ao mesmo tempo, e por isso mesmo, a possibilidade de geração de tecnologias realmente adequadas às características, peculiar idades e limitaçôes de nosso pais é inapelavelmente inibida.

Nos últimos anos, crescentes número de pessoas e organizaçð̋es públicas e privadas vêm desenvolvendo e difundindo novos tipos de tecnologia, aos quais se denominam variavelmente de alternativas, intermediárias, não agressivas ou apropriadas. Tais tipos visam, em princípios, proporcionar um desenvolvimento respeitador das limitaçðes do ecosistema, bem como utilizador de recursos materiais e imateriais disponiveis em certo momento e em determinado lugar.

Um julgamento superficial da literatura sobre essas novas tecnologias pode levar à conclusão de que elas são demasiadamente rústicas e artesanais 
para serem aplicadas a uma economia de grande escala, ou mesmo para serem levadas a sério. No outro extremo, o mero entusiasmo, que caracteriza a posição de muitos defensores de tais tipos de tecnologia, leva a uma freqüente desinformação a respeito das reais possibilidades e limitaçðes dos processos cuja utilização advogam.

\section{Modernidade, uniformidade e eficiência}

Observa-se, em nosso país, monótona insistência na adoção de padrões de desenvolvimento inspirados na simples imitação do que ocorreu com as naçð̃es hoje desenvolvidas, na ingênua suposição de que 'um dia chegaremos lá'. Esta atitude é dominante entre nós apesar da enfática negativa da quase totalidade dos atores que exercem influência e poder no quadro nacional. A cada dia, porém, fica mais evidenciado que as disfunçōes decorrentes desta dominante atitude imitativa se exacerbarão no cenário de inevitável escassez energética mundial e poderão nos levar a um impasse.

Um exemplo é o caso da agricultura: em poucos anos, o Brasil ascendeu à posição de segundo exportador de bens agrícolas do mundo, capaz de produzir milhões de toneladas de grãos, cujas exportaç̃es são elementos vitais em nossa pauta comercial.

Nosso referente é a agricultura americana, cujos índices de produtividade invejamos e cujas técnicas de produção, altamente utilizadoras de capital, estamos aceleradamente copiando. No entanto, vista sob nova perspectiva, que se revela mais e mais importante com a progressiva escassez de petróleo, a da eficiência energética, a agricultura mais moderna do mundo não é um modelo atraente. Ophuls² ao chamar a atenção para este ponto, mostrou que, para produzir três vezes mais alimentos por unidade de área que a India, a celebrada agricultura americana gasta dez vezes mais insumos energéticos, sendo portanto energeticamente menos eficiente.

Basta uma leitura atenta das iniciativas concretas do setor público no campo agrícola para que se chegue à conclusão de que a eficiência energética dos processos produtivos (que, em país altamente dependente como o Brasil, deveria ser considerada crítica) tem importância consideravelmente ofuscada pela preocupação com os volumes de produção obtidos (não importa a que custos em termos de energia...). Confirma-se, assim, a afirmação de Tribe $^{3}$ de que existe uma quase universal tendência de se enfocar os 'impactos', 'resuitados' e 'produtos', ignorando as questőes relativas aos processos, aquelas que se referem ao 'como se chega lá', ao invés do simples, 'onde se chega'.

A mesma preocupação dominante com o 'onde se chega' em detrimento do 'como se chega' é responsável pelo fenômeno social mais complexo e preocupador do setor rural brasileiro: o bóia-fria, trabalhador rural volante, cuja renda e subistência ficam à mercê das necessidades imediatas ou sazonais de mão-de-obra por parte das propriedades agrícolas. A instabilidade e a fragilidade que está assumindo o emprego rural em algumas partes do Brasil são de tal monta que, certamente, a seca que atingiu o sul do país em 1978, teria sido um trágico aprendizado para os planejadores governamentais se tivesse durado, por exemplo, vinte dias a mais, os plantios ter-se-iam frustrado e milhares de trabalhadores volantes, ficado, instantaneamente, sem emprego 4 .

A confusão entre modernização imitativa $e$ desenvolvimento revela-se, também, no culto pela uniformidade e grande escala, ambas inerentes ao nosso modelo. É obvio que este comentário não representa a negação de princípios elementares de tamanho mínimo, tamanho econômico ou economia de escala. No entanto, é patente, em nosso caso, o fascínio pela escala, que resultou na oligopolização dos segmentos mais importantes da economia brasileira, seja pelo governo através de suas empresas, seja por empresas multinacionais ou alguns poucos grupos locais.

Para ilustrar tal ponto, o caso do Programa Nacional do Álcool é adequado. A estratégia adotada, desde o início excluía: a priori, pequenos empresários e processos mais rústicos de produção. 0 programa não estava aparelhado para lidar com empresários isolados, industriais de porte pequeno ou médio-pequeno. Ao contrário, preferiam-se os grupos econômica e financeiramente mais poderosos, capazes de construir unidades de porte médio ou grande, com tecnologia relativamente sofisticada e investimentos de monta. (É de justiça ressaltar que, recentemente, esta orientação vem sendo alterada, ainda que timidamente, como demonstra a aprovação da implantação de mini-usinas, decisão tomada pela Comissão Nacional de Energia em fevereiro do corrente ano; os efeitos desta alteração são, porém, predominantementesimbólicos, por enquanto.)

O raciocínio justificador de tal preferência por grupo relativamentem concentrado de empresário era, como sempre, a preocupação com a eficiência, economia de escala, confiabilidade e uniformidade de processos de produção e produtos. E assim toda uma capacidade capilar de inovação tecnológica e produção de álcool por parte de pequenas empresas fora, de antemão, posta delado. 
Ao contrário do que possa parecer, esta marginalização era, em absoluto, necessária e inevitável. O que está ocorrendo nos Estados Unidos em matéria de álcool é grandemente significativo. Com efeito, nos Estados Unidos, onde, com toda certe$\mathrm{za}$, tecnologias de ponta e grupos empresariais poderosos estão presentes com muito mais freqüência que no Brasil, oálcool utilizado na mistura com a gasolina, batizada de gasohol, é produzido nas mais diversas condições técnicas e empresariais, a partir da batata, do milho, da cana e outros excedentes agrícolas, por cooperativas, empresas de fundo de quintal, mamutes industriais, fazendeiros isolados ou grandes grupos do agribusiness ${ }^{5}$. A diversidade chegou a tal ponto que, pelo menos em um Estado, a legislação que reprimia a atividade dos destiladores clandestinos de bebidas, os moonshuners foi abrandada para permitir-lhes produzir álcool carburante.

ponto que se quer enfatizar é que a produção de álcool, nas quantidades e nos prazos necessários para, realmente, ter algum impacto na resolução da crise energética, demanda, tanto no Brasil como nos Estados Unidos, efetiva e ampla mobilização dos mais diversos segmentos produtivos em prol do mesmo objetivo. A dimensão e a gravidade do problema energético (e por extensão, do problema tecnológico) brasileiro, dependentes que somos de fontes externas de energia, já não permitem a oligopolização de sua solução. Existe, entre nós, potencialmente ao menos, capacidade capilar de inovação e produção que deve ser integralmente mobilizada, a fim de, dentro de suas possibilidades, características e limitações, contribuir para a redução de dependência energética de nosso país.

Ademais, a simples aquisição e ligeira adaptação de tecnologia desenvolvida em e para outros contextos econômicos e sociais não é coerente com os objetivos de desenvolvimento nacional pois, como lembrou corretamente Rogério Cerqueira Leite, "uma sociedade medianamente industrializada não pode sobreviver pela contínua 'aquisição de tecnologia' proveniente de fontes externas. É preciso deSenvolver seus próprios meios de geração de tecnologia"6.

Esta visão, no entanto, contrasta frontalmente com a concepção modernista e triunfalista que se nota em influentes segmentos de nossa sociedade. Guerreiro Ramos, analisando as disfunçð̃es dos conceitos de desenvolvimento, sugeriu a existência de um continuum, dos quais um dos extremos (que denominou de Teoria N) seria caracterizado pela crença de que existe uma lei histórica determinista que impede cada sociedade a tentar atingir os estágios anteiormente ocupados por países ditos modernos ou desenvolvidos. No outro extremo, ao contrário, estaria a Teoria $P$, a qual nega a qualquer sociedade episodicamente hegemônica o caráter de referencial de desenvolvimento, de vez que cada nação contém suas próprias possibilidades de desenvolvimento e estas podem ser inibidas pelo recurso a modelos exógenos?.

\section{Evolução e rumos da tecnologia}

A evolução tecnológica pode ser entendida, de forma drasticamente simplificada, com o auxílio de um modelo descritivo que a divide em cinco etapas $^{8}$ : a primeira consiste no desenvolvimento e uso de ferramentas manuais; a segunda tem como feição saliente o fato de que a eficácia das ferramentas é multiplicada pelo uso de fontes de energia, como animais, moinhos de água ou vento, vapor, etc; a terceira é caracterizada pela especialização das ferramentas; a quarta, pela integração de ferramentas utilizadas para diferentes finalidades, em grandes sistemas como, por exemplo, as linhas de montagem, ferrovias e sistemas telefônicos; finalmente, a quinta etapa é caracterizada pela automação de decisర̃es rotineiras com o auxílio do computador.

Contrariamente àquilo que os partidários incondicionais da livre evolução da tecnologia como solução universal de problemas desejariam, o movimento de reação contra a falta de controle social sobre a geração tecnológica foi ganhando contornos nítidos e teoricamente articulados com o passar do tempo. A publicação do livro de Rachel Carson, Silent Spring, no início dos anos sessenta, é hoje marco fundamental na reação contra a tecnologia sem controle social. Inúmeras linhas de trabalho, cobrindo amplo espectro de preocupações, desde então articuladas, foram, por assim dizer, sistematizadas em 1969 no documento Report of the National Academy of Sciences, Technology: Processes of Assessment and Choice. Em 1973, Tribe ${ }^{9}$, referindo-se ao Report, escreve:

"Poder-se-ia (...) apontar para certas contendências objetivamente identificáveis, convergindo para uma preocupação generalizada com o controle tecnológico, o rápido crescimento da tecnologia, em termos de volume, complexidade e alcance; o período cada vez menor que separa a inovação tecnológica inicial e sua aplicação generalizada, o número crescente de pessoas afetadas pela tecnologia bem como a crescente densidade e interdependência dessas populaçð̋es; a habilidade para perceber conseqüências dos avanços tecnológicos; e a ampliação contínua do número de tecnologias alternativas entre as quais a escolha é possível"' .

As iniciativas de geração de formas tecnológicas alternativas respodem, em termos concretos, à preocupação com os riscos de uma tecnologia a 
qualquer custo, cujas inconveniências e efeitos desastrosos só claramente se avaliam quando os danos provocados são demasiado evidentes para serem desconhecidos ou ocultos. Enquanto que os objetivos gerais de tais tecnologias alternativas são facilmente perceptíveis, o mesmo não ocorre com alguns conceitos fundamentais a elas associados. Como se discutirá adiante, algumas idéias e pressupostos que guiaram o desenvolvimento dessas nvas formas de tecnologia são entendidos de maneira incorreta, ou mesmo de forma simplista ou demasiado literal.

É importante notar que o esforço de geração de tecnologia alternativa é essencialmente diversificado. Diferentes linhas de trabalho se desenvolvem simultaneamente, enfatizando diferentes características dos processos tecnológicos e propondo novas soluções, distanciadas das tradicionalmente conhecidas. A própria semântica das novas formas de tecnologia reflete esta multiplicidade e diversidade conceitual, como se verá a seguir.

\section{Características básicas da tecnologia apropriada}

Entre as diversas denominações utilizadas para descrever as novas formas de tecnologia, as mais correntes são: Tecnologia Alternativa, Tecnologia Intermediária, Tecnologia não Agressiva e Tecnologia Apropriada. Apesar das nuances expressas nas escolhas semânticas, todas descrevem, basicamente, processos desenvolvidos com a mesma preocupação de respeito às capacidades e limitaçð̌es de um determinado sistema físico e social.

$\mathrm{Na}$ denominação de Tecnologia Alternativa, preferida por Dickson ${ }^{10}$, podemos encontrar uma posição contrária à tecnólogia dominante bem como à ideologia industrialista que lhe serve de marco referencial. A dominância de um tipo ortodoxo de tecnologia resultou, na opinião de Dickson, na aceitação do industrialismo como ideologia fundamental dos últimos duezentos anos. Dada a dimensão política inseparável do fenômeno tecnológico, era inevitável que a inviabilidade de outros processos de produção fosse afirmada de maneira dogmática. Assim, a palavra 'alternativa' expressa, com clareza, a busca de caminho radicalmente diverso daquele implícito na ideologia industrialista.

A qualificação de 'intermediária' para a tecnologia, preferida por Schumacher ${ }^{11}$, enfatiza a oposição á crescente (e muitas vezes desnecessária) sofisticação dos processos tecnológicos. No entanto, a busca de simplicidade tem sido constantemente confundida com rusticidade e rudimentaridade. Esta má compreensão leva à errônea noção de que os advogados deste tipo de tecnologia prescrevem a adoção de processos de segurança da classe para países em desenvolvimento. O próprio Schumacher o esclarece: "a ferramenta'apropriada' nem é primitiva nem incuravelmente sofisticada"12.

Esta advertência parece útil pela constância com que alguns processos são rotulados de 'apropriados' independentemente das condições em que empregados. O próprio Schumacher ao descrever seu esforço catequético de introdução de formas intermediárias de tecnologia, refere-se à catalogação de processos e produtos disponíveis para operações rurais de pequena escala como seu passo inicial ${ }^{16}$. Sem diminuir o valor operacional de produtos e processos já existentes, é fundamental, no entanto, enfatizar que a adequação de processos e produtos ao ambiente em que serão utilizados é condição básica e indeclinável das tecnologias apropriadas. Por exemplo, a tecnologia de sistemas de água desenvolvida para Botswana não é, necessariamente, apropriada a outras áreas do mundo, mesmo de níveis de renda semelhantes.

A catalogação de processos e produtos disponíveis, que se prestem a operaçð̃es de pequena escala, com baixo ou nulo efeito poluente, simples de manejar e de manter, é tarefa importantíssima para demonstrar a viabilidade de soluções diferentes das dominantes. No entanto, não deve ser perdido de vista que os limites da tecnologia apropriada são os limites da criatividade humana em utilizar, eficientemente, os fatores disponíveis. Torna-se assim, evidente que a tecnologia apropriada não consiste num grupo de produtos acabados mas, essencialmente, na capacidade de inventar novos e mais adequados processos de produção.

Cabe agora uma análise das características comumente associadas com os processos ditos apropriados, como a intensidade do fator trabalho, a simplicidade e a pequana escala. Vejamos, incialmente o nivel de intensidade do fator trabalho: é provável que os processos apropriados sejam mais utilizadores de mão-de-obra, mais isto não é, invariavelmente, o que ocorre. Estudos realizados em países em desenvolvimento ${ }^{17}$ mostraram que, mesmo em presença de abundantes contingentes de mão-de-obra, muitos processos nela baseados não são os mais efetivos, por força de condiçð̋es como um nível mínimo de padronização dos produtos obtidos ou o custo relativo de mão-de-obra em zonas. O Intermediate Technology Group, de Londres, por exemplo, concluiu que, em muitos casos, uma combinação entre processos capital-intensivos e trabalhos-intensivos era o ideal ${ }^{18}$.

$\mathrm{Na}$ realidade, alguns processos apropriados são tão poupadores de trabalho como os que vieram a substituir: as células fotovoltaicas e os coletores de 
energia solar são exemplos de tecnologias que, apesar de claramente apropriadas a grande número de lugares, não acrescentam novos empregos e talvez até os reduzam.

A simplicidade e rusticidade são outras qualificações enganosas; na ânsia de desenvolver processos mais próximos da natureza e mais simples de operar e manter, os pesquisadores têm resvalado, freqüentemente, para técnicas tão rústicas e primitivas que só fariam sentido em sociedades tribais em níveis pré-históricos de evolução. Contrariamente ao que tais pesquisadores imaginam, processos ditos apropriados podem assumir formas muito sofisticados. O exemplo das células fotovoltaicas para transformação de luz em energia elétrica, originalmente um processo tencológico espacial, é esclarecedor. Alguns processos milenares, como a utilização da energia eólica, só ganham viabilidade quando aperfeiçoados com o auxílio de técnicas requintadas. Os modernos moinhos de vento, por exemplo incorporam avanços na aerodinâmica, materiais e engineering que só foram possibilitados pelo crescimento explosivo da indústria aeronáutica e espacial.

Por fim, o conceito da pequana escala também merece qualificação. Melhor seria que falássemos em escalas controláveis como as que poderão surgir, no campo energético, quando as fontes solares puderem ser exploradas a níveis de pequenas comunidades ou mesmo vizinhanças. No entanto, seria ingênuo admitir que todos os problemas passiveis de solução podem ser reduzidos a escalas minúsculas e como tal tratados.

Em conclusão, as formas apropriadas de tecnologia não são universais, o objetivo essencial da tecnologia apropriada é o desenvolvimento de uma capacidade processadora apta a combinar, adequadamente, os fatores disponíveis; as características de maior intensidade de mão-de-obra, rusticidade, simplicidade e pequena escala devem ser considerados como prováveis mas não indispensáveis.

Os processos tecnológicos descritos revestem-se de pleno sentido funcional no contexto do quadro referencial da Teoria da delimitação dos sistemas sociais formulados pelo professor Guerreiro Ramos ${ }^{19}$.

\section{Tecnologia e teoria apropriadas}

A multidimensionalidade da tecnologia é bem conhecida. Apesar disto, ela é, freqüentemente, tratada de maneira simplista e linear, como mera viabilizadora de processos de produção de bens e serviços. Esta unilateralidade na observação da tecnologia responde à mesma lógica aparente de que os sis- temas sociais parecem cativos à absoluta dominância do mercado como determinante organizacional.

Não caberia, aqui, uma análise detalhada desse conceito, tarefa já empreendida pelo próprio professor Ramos em diversas ocasiōes em que expôs o embasamento teórico e as categorias de sua Teoria da delimitação dos sistemas sociais, que deplora esta subordinação dos sistemas sociais ao mercado. Cabe apenas lembrar que o mesmo autor oferece, alternativamente, uma visão paraeconômica do funcionamento dos sistemas sociais, de modo a reduzir o mercado à sua verdadeira função. Parece útil, porém, uma tentativa de enquadramento das novas formas de tecnologia até agora discutidas, dentro de algumas categorias delimitativas.

Uma primeira e fundamental coerência entre as propostas de tecnolgia apropriada e uma teoria delimitativa dos sistemas sociais decorre do caráter contextual de ambas. Ao enfatizar que os vetores dos processos de evolução dos sistemas sociais estão contidos neles próprios, a teoria delimitativa legitima as propostas de tecnologia compativel com a disponibilidade de fatores locais, a maximização de suas potencialidades e o respeito às suas limitaçð̋es.

Outra importante aproximação entre as duas propostas decorre das conseqüências que podem ser prognosticadas a partir da adoção de formas de tecnologia apropriadas: a auto-suficiência, a selfreliance, a acessibilidade do cidadão aos processos de produção de bens e serviços permitirão, sem dúvida, a viabilização dos enclaves sociais de que fala Guerreiro Ramos, enclaves estes que se relacionarão de maneira controlada com o mercado e procurarão desenvolver uma identidade própria, bem como manter íntegros seus valores peculiares.

A concepção delimitativa não significa, porém, ingênua restauração dos 'bons tempos de outrora', nem muito menos ataque dogmático aos males devidos ao mercado, ao individualismo utilitarista e ao mercantilismo que permeia as relaçס̃es sociais de nosso tempo. Ao contrário, reconhece a proposta delimitativa que vivemos a última etapa de um período mercado por transformaçð̋es econômicas, sociais, físicas e políticas sem precedentes e que qualquer proposta reorganizadora dos sistemas sociais de levar em consideração a estrutura dos recursos finitos.

Ao localizar e categorizar, nos sistemas sociais, fenômenos e manifestaçø̃es que, em cocepção teórica mais restritiva, seriam relegados à obscura posição no setor terciário, a Teoria da delimitação estabelece as bases para que tais fenômenos e manifestaçð̋es seja especializada e convenientemente tratados e preservados, bem como tenham seu valor (eventualmente, até de mera fruição estéti- 
ca) reconhecido como socialmente útil e importante.

De acordo com a concepção delimitativa, um dos papéis mais relevantes dos governos será, exatamente, o de desenvolver mecanismos de percepção para identificar e categorizar os diferentes enclaves sociais (economias, isonomias e fenonomias) e, através de políticas apropriadas, proteger e preservar o funcionamento dos mesmo enclaves. Assim, as propostas de uma tecnologia apropriada, ou seja, em linha com a disponibilidade de fatores, guarda estrita coerência com a proposta delimitativa e nela encontra sólida legitimação teórica. Éaltamente significativa, por exemplo, a afinidade entre os conceitos delimitativos e a pesquisa tendente a desenvolver novas formas de tecnologia e novos estilos de vida apropriados à estrutura finita do planeta, às tolerâncias do ecossistema e à disponibilidade local de recursos. Entre tais pesquisas, destacam-se as que vêm sendo empreendidas pelo New Alchemy Institute e que John Todd descreve em recente publicação20.

A observação de inúmeras iniciativas correntes no Brasil demonstra que alguns dos princípios delimitativos vêm sendo empregados no país, ainda obviamente, não enquadrados teoricamente no teorema paraeconômico proposto por Guerreiro Ramos. Um exemplo claro de 'isonomia' (um dos conceitos delimitativos básicos) é a Campanha Nacional de Educandários da Comunidade - C.N.E.C., entidade sem fins lucrativos, que objetiva mobilizar as comunidades locais para organizarem seus serviços de ensino. Não conheço o funcionamento interno da C.N.E.C., que é, certamente, uma burocracia que paga salários, recebe dinheiro, tem diretoria, paga contas, etc. Entretanto, o trabalho que realiza está impregnado de algo mais que a simples execução de tarefas administrativas ou burocráticas, pois persegue objetivo de organizar e preservar as comunidades, criando, com isto, condiçðes objetivas de manutenção de seus valores. Entidades como a FINEP cumprem função claramente delimitativa, ao apoiar e proteger iniciativas científicas e tecnológicas inovadoras, as quais, se submetidas à análise por critérios míopes de apuração de custo e benefício, seriam consideradas irrelevantes.

Em inúmeras organizaçð̃es, observa-se que é possível conviver com as realidades da economia de mercado e, ao mesmo tempo, não permitir que o ethos do mercado domine totalmente o sistema social. Ocorre-me, como exemplo, a Cooperativa Agrícola de Entrerios, em Guarapuava, no Paraná, formada por suábios e seus descendentes. Estes conseguem, a um tempo, relacionar-se com o mercado (de forma aliás exemplarmente lucrativa) e guardar a identidade cultural e a coesão do seu gru- po. Trata-se, assim, de um exemplo de convivência limitada e controlada com os valores do mercado, de que fala a Teoria da delimitação.

Enfim, os exemplos estão à mostra para serem capturados pelo observador atento. O papel da TeOria da delimitação dos sistemas sociais foi o de fornecer as categorias conceituais para identificar e entender tais exemplos dentro de uma nova perspectiva. A aceitação deste novo paradioma implica em reconhecer que o funcionamento dos sistemas sociais pode assumir formas significativamente diversas daquelas a que fomos acostumados por força da dominância dos valores do mercado na organização de tais sistemas.

No caso da tecnologia, a compreensão de que existem formas alternativas e mais apropriadas do que as correntes, é urgente e fundamentalmente necessária. A virtual oligopolização de setores essenciais da economia brasileira impede a plena utilização do nosso potencial de geração de processos tecnológicos apropriados ao país. Em outras palavras, nem as empresas multinacionais (cujas decisões são ditadas por uma lógica supranacional) devem ser consideradas parceiros naturais em uma luta por tecnologia endógena, nem as grande empresas estatais (projetadas contra a competição por uma duvidosa interpretação de interesse nacional e soberania) se sentem estumuladas à inovação. Como demonstrou Wanderley Guilherme dos Santos $^{21}$, grandes estruturas públicas e privadas podem ser altamente inovativas mas, para tanto, necessitam estar expostas a uma situação de competitividade, o que não é, exatamente, o caso brasileiro.

É portanto, tarefa inadiável, desenvolver políticas e açőes que permitam a plena expressão da capacidade processadora, inovadora e geradora de tecnologias que existem (ao menos potencialmente) em amplas faixas do sistema social brasileiro e que, atualmente, são esquecidas como contribuidoras do esforço nacional de criação de riqueza.

Neste contexto de considerações, adquire pleno sentido o fato (ressaltado pela imprensa, com toda justiça) de que, em 1930, graças aos ideiais de gente como Eduardo Sabino de Oliveira, engenheiro recém-formado, de 25 anos de idade, o Brasil produzia álcool carburante em grande escala para os padrőes da época ${ }^{22}$. Exatamente o que um grande aparato burocrático vem tentando fazer agora, cinqüenta anos depois...

\section{Álcool no Brasil e tecnologia apropriada}

Pode o projeto de produção em larga escala de álcool no Brasil ser considerado um exemplo de 
tecnologia apropriada aplicado ao nosso país? A resposta é um cauteloso sim, com várias qualificaçø̃es.

Em primeiro lugar, é alternativa muito mais consistente com a nossa disponibilidade de fatores do que a importação e tranformação industrial do petróleo. Trata-se, no caso doálcool, de processos técnicos bastante simples, rudimentares mesmo. Apesar da economicidade relativa de processos mais difundidos exigir escala mínima de produção superior àquilo que consideraríamos pequena escala, há alternativas técnicas para produzir, virtualmente, qualquer quantidade do produto. Além de utilizar recursos típicos de nossa estrutura agrícola, os recursos naturais existentes no Brasil e a solaridade natural, permitem a utilização de recursos humanos representados pela mão-de-obra e pelo empresariado agrícola e agroindustrial, principalmente - que está habilitado para as tarefas de produção e comercialização do produto.

Adicionalmente, ao resultar de um processo agroindustrial de baixa tecnificação, o álcool se distancia marcadamente do petróleo, cuja industrialização é caracterizada pela alta sofisticação das unidades de refino e processamento petroquímico. Enquanto que, no setor petrolífero, a renda ou é tranferida para o exterior ou altamente concentrada em pequenos segmentos da economia brasileira, no caso do álcool, a renda pode ser distribuída difusamente por enorme número de atividades. Esta redistribuição de renda não será, apenas, de caráter intersetorial pois, contrariamente ao setor petrolífero geograficamente concentrado, as atividades ligadas ao álcool poderão se distribuir por grande parcela do território nacional.

No entanto, graves disfunçðes necessitam Ser evitadas. Em interessante avaliação do programa23, Yang e Trinidade já alertavam em 1978 para o risco de submeter a produção de álcool às contingências do mercado internacional de acúcar, caso continuasse a preferência por destilarias anexas às usinas de acúcar; advogavam, também, corretamente em meu ponto de vista, que a base estratégica do programa do álcool seja constituída de pequenas unidades, distribuídas ao longo do território nacional, utilizando matéria-prima localmente disponivel, ao invés de concentrar a produção em alguns estados (como São Paulo) e, em seguida, tranportar para outros, os excedentes de álcool não consumidos regionalmente. Alguns sinais, ainda tímidos, de redirecionamento do programa nesses sentidos, são bastante animadores.

Em síntese, se formos capazes de aproveitar toda a capacidade produtiva e inovadora latente no país para a produção de álcool sem preocupações de simetrias, hegemonias, ou modernidade exces- siva; se formos capazes de estimular as mais diversas formas e arranjos econômicos e organizacionais para executar o programa; se resistirmos à tentação de redirecionar terras atualmente ocupadas com alimentos para produzir cana o que aliás, já esta acontencendo; se formos suficientemente lúcidos para impedir que se implante no país uma cultura canavieira de padrōes havaianos; se resistirmos à tentação de 'organizar', 'coordenar' , 'articular', 'maximizar', 'otimizar' demasiadamente a produção (bem como praticar outros verbos do glossário tecnoburocrático que, em última análise, se destinam a concentrar e controlarł, a produção em larga escala, de álcool - o Brasil tornar-se-á episódio representativo de bem sucedida utilização de tecnologias apropriadas.

Se porém, insistirmos ria miopid corn que temos tratado alguns aspectos essenciais do processo de inovação e produção; na resignação com que temos tratado nossa vulnerabilidade face ao exterior; na fascinação com que encaramos os padrões exógenos de modernidade e desenvolvimento - o nosso programa será, apenas, uma oportunidade a mais perdida para a afirmação de uma tecnologia apropriada às características brasileiras.

\section{Notas}

1. Professor-visitante do curso de pós-graduaçăo em administração da Universidade Federal de Santa Catarina - U.F.S.C.

2. OPHULS, William. Economy and the politics of scarcity. San Francisco, W.H. Freeman and Co., 1977. p. 3.

3. TRIBE, Lawrence. Technology assessment and the fourth discontinuity: the limits of instrumental rationality. Southern Californis Law Review. 46: 631, 1973.

4. Ver, neste número, artigo de Celso Antônio Bandeira de Mello, sob o título Eficácia das normas constitucionais sobre justiça social onde se adverte sobre a inconstitucionalidade das políticas econômicas que conduzem à retração na oferta de emprego (nota do editor)

5. Em recente entrevista à TV, um industrial de Los Angeles, que fornece gasohol para a patrulha rodoviária da Califórnia, declarou que seus investimentos totais atingiram, apenas, $\$ 85,000$.

6. LEITE, Rogério C. Cerqueira. A Agonia da tecnologia nacional. São Paulo, Duas Cidades. p. 55, 1978.

7. RAMOS, Alberto Guerreiro. Modernization; toward a possibility model, in Developing nations: quest for a model. Editado por W.A. Beling e G.O. Totten. Van Nostrand Reinhold Comp. 1970.

8. ESTADOS UNIDOS DA AMÉRICA. Congresso. Câmara de Representantes. Science, technology and american diplomacy, 1977.

9. TRIBE, Lawrence. obra citada. p. 620.

10. DICKSON, David. The Politics of alternative technology New York, Universe Books, 1975.

11. SCHUMACHER, E.F. Intermediate technology, the center magazine. 1975 . v. 8, n. 1, p. 43-49.

12. SCHUMACHER, E.F. ibid., p. 43 
13. LOVINS, Amory. Soft energy paths. Cambridge, Massachusetts, Ballinger Publishinglo, 1977.

14. ESTADOS UNIDOS DA AMÉRICA. USAID. Proposal for program in appropriate tenchology. 1978.

15. ibid.

16. SCHUMACHER, E.F. obra citada, p. 44.

17. Como os descritos por Marilyn Carr, em Economically appropiate technology for developing countries, 1976.

18. ibid.

19. O novo livro do prof. Ramos. The New sciense of organiza- tions a ser brevemente publicado cobre, em detalhes, a Teoria de delimitação formulação pelo autor.

20. TODD, John. Technologies for a new life style. IN: MEADOWS, D.L. et alii ed. Alternatives to growth. Cambridge, Massachusetts, Ballinger Publishinglo, 1977.

21. SANTOS, Wanderley, Guilherme dos. Serendipity in innovation oraganizational. 1972.

22. Em entrevista ao Jornal do Brasil em 20 de maio de 1979, o engenheiro descreve sua experiência.

23. YANG, Victor e TRINIDADE, Sérgio. The Brazilian gasohol program, Development Digest. 1979. v. 17, n. 3. 